\title{
(i) \\ Thrombocytopenia as a Marker of Patient Outcome in Medical Intensive Care Unit
}

Check for updates

\author{
Abbas Fadaei ${ }^{1}$, Seyed Mojtaba Heidari ${ }^{2}$, Maryam Alizadeh \\ Chamkhaleh ${ }^{3}$, Mohammad Amin Abbasi ${ }^{4, *}$
}

1 Department of Pulmonology and Intensive Care Medicine, Shahid Labbafinejad Hospital, Shahid Beheshti University of Medical Sciences, Tehran, Iran

2 Department of Medicine, Shahid Labbafinejad Hospital, Shahid Beheshti University of Medical Sciences, Tehran, Iran

${ }^{3}$ Student Research Committee, School of Medicine, Iran University of Medical Sciences, Tehran, Iran

${ }^{4}$ Department of Medicine, Clinical Research Development Unit, Firoozabadi Hospital, Iran University of Medical Sciences, Tehran, Iran

*Corresponding author: Mohammad Amin Abbasi, Department of Medicine, Clinical Research Development Unit, Firoozabadi Hospital, Iran University of Medical Sciences, Tehran, Iran. Tel: +98-55902064; E-mail: DOI: $10.21859 / \mathrm{ijcp}-03042$ abbasi.ma@iums.ac.ir

\begin{abstract}
Introduction: Thrombocytopenia is a common hematologic disorder observed in many pathological conditions in critically ill patients. The current study aimed at investigating the prevalence of thrombocytopenia and its relationship with the length of stay and mortality among intensive care unit (ICU) patients.

Methods: The current prospective cohort study enrolled 150 patients consecutively admitted to the medical ICU during a nine-month period. Patients' baseline characteristics and underlying diseases were recorded. Laboratory findings and admission mean platelets and platelet counts on the 3rd day of admission were obtained. Patients were divided into thrombocytopenic (platelet count of less than $150 \times 109 / \mathrm{L}$ or decrease of platelet to more than 50\%) and non-thrombocytopenic groups according to the $3 \mathrm{rd}$ day platelet count.

Results: Thrombocytopenia was detected in 53(35\%) patients while 13 patients $(8.6 \%)$ had severe thrombocytopenia (platelets count $<50 \times 109 / \mathrm{L})$. ICU stay and mortality were significantly higher in patients with thrombocytopenia compared with non-thrombocytopenic patients $(16 \pm 2.7$ vs $12 \pm 2.4$ days, $\mathrm{P}=0.01)$ and $(45.5 \%$ vs $37.3 \%, \mathrm{P}=00.1$ ) respectively.

Conclusions: Platelet might be considered as a prognosis monitor in ICU settings. Severe thrombocytopenia could be mentioned as a poor prognostic factor for increased mortality and prolonged hospitalization period in ICU patients.
\end{abstract}

\section{INTRODUCTION}

Thrombocytopenia is a frequent abnormality in intensive care unit (ICU) patients that varies from $13 \%$ to $44 \%$ [1]. Thrombocytopenia is often multi-factorial and it is not easy to determine the exact cause of thrombocytopenia in ICU. It may cause higher mortality in critically ill patients [2]. Thrombocytopenia is defined as platelet count less than $150 \times 10^{9} \cdot \mathrm{L}^{-1}$, but for ICU patients the amount is less than $100 \times 10^{9} . \mathrm{L}^{-1}$, and platelet counts less than $50 \times 10^{9} \cdot \mathrm{L}^{-1}$ is known as severe thrombocytopenia $[3,4]$. In addition to platelet count, mean platelet volume (MPV) is one of the factors that indicate platelet function [5]. Higher MPV values are associated with increased platelet activation. Platelet count and MPV are simple methods to monitor patient's condition [6-10]. Thrombocytopenia may increase the risk of bleeding as well as thrombosis caused by platelets activation, according to the underlying mechanism [11, $12]$. 
Thrombocytopenia in intensive care unit may cause bleeding, organ failure, and increase the length of hospitalization $[3,13,14]$.

Etiologies of thrombocytopenia in critically ill patients are widely studied. Mechanisms that can result in thrombocytopenia in critically ill patients are hemodilution (decreased concentration of cells and solids in the blood resulting from gain of fluid), more platelet consumption (due to massive tissue trauma), bleeding, platelet sequestration, decreased platelet production, sepsis, and DIC (disseminated intravascular coagulation) [15-17]. It is necessary to make the etiologic diagnosis to accommodate the patients benefit from appropriate treatment. Association between thrombocytopenia and prognosis of patients admitted in ICU was declared recently. The current study aimed at investigating the prevalence of thrombocytopenia and its relationship with the length of stay in ICU and mortality among ICU patients.

\section{METHODS}

The current histological cohort study enrolled 150 patients above 18 years old consecutively admitted to ICU for more than two days ( 83 male and 67 female). This study protocol was approved by the Ethics Committee of Shahid Beheshti University of Medical Sciences. Patients had normal platelet range (more than $\left.150 \times 10^{9} . \mathrm{L}^{-1}\right)$ in the beginning, and were followed until they were discharged or died.

Patients' baseline and demographic characteristics such as age, gender, and body mass index (BMI) were evaluated.

Thrombocytopenia was defined as more than 50\% decrease in platelet count or platelet count less than $150 \times 10^{9} . \mathrm{L}^{-1}$ on the $3 \mathrm{rd}$ day. Patients were divided to thrombocytopenic and non-thrombocytopenic groups.

\section{Statistical Analysis}

Data were presented as means \pm SD and qualitative variables as frequency (percentage). Statistical analyses were performed with SPSS software for Windows (Statistical Product and Service Solutions, version 20.0, SSPS Inc., Chicago, IL, USA). Student $t$ test for quantitative variables and chi-squared test for quantitative variables were used. $P$ values less than 0.05 were considered as statistically significant.

\section{RESULTS}

Mean age of patients was $58.8 \pm 11.9$ years (range $46-$ 73). Patients' characteristics are shown in Table 1.

From 150 patients (83 male and 67 female) thrombocytopenia was detected in 53(35\%) patients while $13(8.6 \%)$ patients had severe thrombocytopenia (platelet count $<50 \times 10^{9} / \mathrm{L}$ ). Thrombocytopenia on the $3 \mathrm{rd}$ day of admission was detected in $40.2 \%$ and $31.3 \%$ of females and males, respectively, which was not statistically different $(\mathrm{P}=0.1)$. As shown in Table 2 , admission mean platelets were similar in patients with thrombocytopenia and non-thrombocytopenic patients $\left(243674 \times 10^{6} \pm 7648 \times 10^{6} / \mathrm{L}\right.$ and $26154 \times 10^{6} \pm 8031 \times$ $10^{6} / \mathrm{L}$, respectively; $\mathrm{P}=0.6$ ), while the platelet counts on days 3-5 after admission significantly decreased in patients with thrombocytopenia $\left(243674 \times 10^{6} \pm 7648 \times\right.$ $10^{6} / \mathrm{L}$ and $26154 \times 10^{6} \pm 8031 \times 10^{6} / \mathrm{L}$, respectively; $\mathrm{P}$ $=0.6)$. Overall duration of hospitalization was $13.41 \pm 2.6$ days, which was significantly higher in patients with thrombocytopenia compared with nonthrombocytopenic patients ( $16 \pm 2.7$ vs $12 \pm 2.4$ days, respectively $\mathrm{P}=0.01$ ).

Table 1: Patients baseline characteristics
\begin{tabular}{|lc|}
\hline & $\begin{array}{c}\text { Thrombocytopenic } \\
(\mathbf{n}=\mathbf{1 5 0})\end{array}$ \\
Age (years) & $58.74 \pm 11.93$ \\
Gender (male) & $83(55.3 \%)$ \\
BMI (Kg/m2) & $34.63 \pm 6.72$ \\
Creatinine (mg/d) & $1.23 \pm 0.68$ \\
Platelet on admission $\left(\times \mathbf{1 0}^{9} / \mathbf{L}\right)$ & $259364 \pm 7438$ \\
Admission cause & \\
Respiratory failure & $63(42 \%)$ \\
Septic shock & $34(22.7 \%)$ \\
Renal failure / ESRD & $53(35.3 \%)$ \\
Systolic blood pressure (mmHg) & $137.2 \pm 11.1$ \\
Heart rate (bpm) & $73.6 \pm 6.7$ \\
Hospitalization duration $(\mathbf{d a y s})$ & $13.6 \pm 2.5$ \\
Mortality (\%) & $60(40 \%)$ \\
\hline
\end{tabular}

Data in are presented as No. (\%) or Mean \pm SD.

ESRD: end stage renal disease; bpm: beat per min

The current study results demonstrated significant difference in ICU mortality between thrombocytopenic and non-thrombocytopenic patients $(45.5 \%$ vs $37.3 \%$, $\mathrm{P}$ $=0.01)$. The current study investigated the effect of sever thrombocytopenia (platelet count $<50 \times 10^{9} / \mathrm{L}$ ) on ICU mortality. As shown in Table 3, sever thrombocytopenia was associated with increased mortality compared with thrombocytopenic patients who had platelet count more than $50 \times 10^{9} / \mathrm{L}$ (OR 1.4; $95 \%$ confidence interval $(\mathrm{CI}): 1.2-1.8 ; \mathrm{P}=00.1)$.

\section{DISCUSSION}

The prevalence of thrombocytopenia among 150 patients ( 83 male and 67 female) admitted to ICU was detected in 53(35\%) patients while 13 patients $(8.6 \%)$ had severe thrombocytopenia (platelet count $<50 \times$ $10^{9} / \mathrm{L}$ ). The current study results were consistent with those of previous studies reporting that thrombocytopenia can vary from $30 \%$ to $50 \%$ [1]. The wide range of prevalence might be due to different inclusion or exclusion criteria, condition or stage of patients, and quality of hospitalization. 
Table 2: Variables between Groups

\begin{tabular}{|lccc|}
\hline & Thrombocytopenic $(\mathbf{n}=\mathbf{5 3})$ & Non-Thrombocytopenic $(\mathbf{n}=\mathbf{9 7})$ & P value \\
\hline Age $($ years) & $61.3 \pm 12.6$ & $57.2 \pm 11.7$ & 0.4 \\
Gender $(\mathbf{m a l e})$ & $26(49 \%)$ & $57(58.7)$ & 0.1 \\
BMI $(\mathbf{K g} / \mathbf{m} \mathbf{2})$ & $36.5 \pm 7.6$ & $33.2 \pm 6.5$ & 0.3 \\
Creatinine (mg/dl) & $1.2 \pm 0.8$ & $1.3 \pm 0.6$ & 0.2 \\
Platelet on admission $(\mathbf{\times 1 0} / \mathbf{L})$ & $243674 \pm 7648$ & $326154 \pm 8031$ & 0.6 \\
Systolic blood pressure (mmHg) & $142.8 \pm 11.4$ & $138.7 \pm 9.6$ & 0.2 \\
Heart rate (bpm) & $78.2 \pm 5.3$ & $83.6 \pm 4.7$ & 0.1 \\
Hospitalization duration (days) & $16.1 \pm 2.7$ & $12.3 \pm 2.4$ & 0.01 \\
Mortality (\%) & $24(45.4 \%)$ & $36(37.5 \%)$ & 0.001 \\
\hline
\end{tabular}

Data in are presented as No.(\%) or Mean \pm SD.

BMI: Body Mass Index; bpm: beat per min

Table 3: Severe Thrombocytopenia and Intensive Care Unit Admission Outcome

\begin{tabular}{|c|c|c|c|}
\hline & $\begin{array}{l}\text { Severe Thrombocytopenia Platelet }<50 \times 10^{9} / \mathrm{L} \\
\qquad(\mathrm{n}=13)\end{array}$ & $\begin{array}{l}\text { Thrombocytopenia Platelet: } 50-150 \times 10^{9} / \mathrm{L} \\
\qquad(\mathrm{n}=40)\end{array}$ & $\begin{array}{c}\mathbf{P} \\
\text { value }\end{array}$ \\
\hline Discharge (\%) & $5(39 \%)$ & $24(60 \%)$ & 0.01 \\
\hline Expire (\%) & $8(61 \%)$ & $16(40 \%)$ & 0.01 \\
\hline
\end{tabular}

Data in are presented as No. (\%)

In the current study, thrombocytopenia was detected in $35 \%$ of patients, which was lower than that of the study by Thiery-Antier et al. reporting that $48.4 \%$ of patients had thrombocytopenia and $14.8 \%$ of them had platelet count $<50 \times 10^{9} / \mathrm{L}[18]$. According to the current study, thrombocytopenia was associated with increased hospitalization period and mortality rate in critically ill patients. The current study findings were similar to those of some studies suggesting that thrombocytopenia increases ICU length of stay and mortality in patients admitted to ICU [19].

Thrombocytopenia is a common disorder in ICU patients and prolonged thrombocytopenia is assumed to be associated with increased mortality. Due to the importance, many studies investigated the etiology of thrombocytopenia and its role on the prognosis in critically ill patients, but the exact reason is not clarified. It is believed that thrombocytopenia is multi-factorial and the fall in platelet count is caused by different mechanisms. Five major mechanisms such as hemodilution, increased platelet consumption, decreased platelet production, increased platelet sequestration, and platelet destruction due to immune mechanisms seem responsible for thrombocytopenia [20]. According to the authors' best knowledge there are limited data on sever thrombocytopenia in ICU patients $[21,22]$. The current study also investigated the effect of sever thrombocytopenia (platelet count $<50 \times 10^{9} / \mathrm{L}$ ) on ICU mortality. The study observed sever thrombocytopenia in $8.3 \%$ of patients associated with increased mortality among patients with thrombocytopenia (OR 1.4; CI95\% 1.2-1.8; P=00.1). Marco-Schulke et al., demonstrated a total of $11.7 \%$ developed sever thrombocytopenia in ICU patients, which was higher than our results [23].
The current study results showed that sever thrombocytopenia increased with mortality rate and low platelet scale was known as a poor prognostic factor. Although decrease in platelet count in critically ill patients is common and can be observed in different conditions, occurrence of sever thrombocytopenia reflects DIC and is correlated with coagulation disorders [24]. One of the most important causes of thrombocytopenia in ICU patients is bacterial infection, known as sepsis. During a septic shock, platelets can also be either activated by inflammatory mediators or directly by microorganism components [25]. Some studies show higher mortality in patients with acute kidney injury undergoing dialysis with thrombocytopenia fortifying inflammatory process [26]. The role of platelet in increasing mortality range is possibly due to its important role in inflammatory procedure and not in coagulation pathway.

\section{CONCLUSIONS}

Platelet alternation is one of the common hematologic abnormalities occurred by various conditions that might be considered as a prognosis monitor in ICU setting. Severe thrombocytopenia could be mentioned as a poor prognostic factor for increased mortality and prolonged hospitalization period in ICU patients.

\section{Author's Contribution}

Abbas Fadaei: data collection and supervision

Seyed Mojtaba Heidari: data collection

Mohammad Amin Abbasi: data analysis and writing

Maryam Alizadeh Chamkhaleh: data collection and writing

\section{Conflicts of Interests}

None declared. 


\section{REERENCES}

1. Thiele T, Selleng K, Selleng S, Greinacher A, Bakchoul T. Thrombocytopenia in the intensive care unit-diagnostic approach and management. Semin Hematol. 2013;50(3):23950. doi: 10.1053/j.seminhematol.2013.06.008 pmid: 23953341

2. Hui P, Cook DJ, Lim W, Fraser GA, Arnold DM. The frequency and clinical significance of thrombocytopenia complicating critical illness: a systematic review. Chest. 2011;139(2):271-8. doi: 10.1378/chest.10-2243 pmid: 21071526

3. Crowther MA, Cook DJ, Meade MO, Griffith LE, Guyatt GH, Arnold DM, et al. Thrombocytopenia in medical-surgical critically ill patients: prevalence, incidence, and risk factors. $\mathrm{J}$ Crit Care. 2005;20(4):348-53. doi: 10.1016/j.jcrc.2005.09.008 pmid: 16310606

4. Stanworth SJ, Walsh TS, Prescott RJ, Lee RJ, Watson DM, Wyncoll DL, et al. Thrombocytopenia and platelet transfusion in UK critical care: a multicenter observational study. Transfusion. 2013;53(5):1050-8. doi: 10.1111/j.15372995.2012.03866.x pmid: 22928908

5. Tuncel T, Uysal P, Hocaoglu AB, Erge DO, Karaman O, Uzuner N. Change of mean platelet volume values in asthmatic children as an inflammatory marker. Allergol Immunopathol (Madr). 2012;40(2):104-7. doi: 10.1016/j.aller.2011.03.007 pmid: 21621316

6. Becchi C, Al Malyan M, Fabbri LP, Marsili M, Boddi V, Boncinelli S. Mean platelet volume trend in sepsis: is it a useful parameter? Minerva Anestesiol. 2006;72(9):749-56. pmid: 16871155

7. Canpolat FE, Yurdakok M, Armangil D, Yigit S. Mean platelet volume in neonatal respiratory distress syndrome. Pediatr Int. 2009;51(2):314-6. doi: 10.1111/j.1442-200X.2009.02820.x pmid: 19379270

8. Chu SG, Becker RC, Berger PB, Bhatt DL, Eikelboom JW, Konkle B, et al. Mean platelet volume as a predictor of cardiovascular risk: a systematic review and meta-analysis. J Thromb Haemost. 2010;8(1):148-56. doi: 10.1111/j.15387836.2009.03584.x pmid: 19691485

9. Kostrubiec M, Labyk A, Pedowska-Wloszek J, HrynkiewiczSzymanska A, Pacho S, Jankowski K, et al. Mean platelet volume predicts early death in acute pulmonary embolism. Heart. 2010;96(6):460-5. doi: 10.1136/hrt.2009.180489 pmid: 19910287

10. Onder I, Topcu S, Dokmetas HS, Turkay C, Seyfikli Z. Platelet aggregation size and volume in chronic obstructive pulmonary disease. Mater Med Pol. 1997;29(1-4):11-3. pmid: 10214464

11. Lim SY, Jeon EJ, Kim HJ, Jeon K, Um SW, Koh WJ, et al. The incidence, causes, and prognostic significance of new-onset thrombocytopenia in intensive care units: a prospective cohort study in a Korean hospital. J Korean Med Sci. 2012;27(11):1418-23. doi: 10.3346/jkms.2012.27.11.1418 pmid: 23166427

12. Watson SP. Platelet activation by extracellular matrix proteins in haemostasis and thrombosis. Curr Pharm Des. 2009;15(12):1358-72. pmid: 19355974

13. Ben Hamida C, Lauzet JY, Rezaiguia-Delclaux S, Duvoux C, Cherqui D, Duvaldestin P, et al. Effect of severe thrombocytopenia on patient outcome after liver transplantation. Intensive Care Med. 2003;29(5):756-62. doi: 10.1007/s00134-003-1727-x pmid: 12677370
14. Nydam TL, Kashuk JL, Moore EE, Johnson JL, Burlew CC, Biffl WL, et al. Refractory postinjury thrombocytopenia is associated with multiple organ failure and adverse outcomes. J Trauma. 2011;70(2):401-6; discussion 6-7. doi: 10.1097/TA.0b013e31820b5c85 pmid: 21307741

15. Drews RE. Critical issues in hematology: anemia, thrombocytopenia, coagulopathy, and blood product transfusions in critically ill patients. Clin Chest Med. 2003;24(4):607-22. pmid: 14710693

16. Vanderschueren $\mathrm{S}$, De Weerdt A, Malbrain $\mathrm{M}$, Vankersschaever D, Frans E, Wilmer A, et al. Thrombocytopenia and prognosis in intensive care. Crit Care Med. 2000;28(6):1871-6. pmid: 10890635

17. Strauss R, Wehler M, Mehler K, Kreutzer D, Koebnick C, Hahn EG. Thrombocytopenia in patients in the medical intensive care unit: bleeding prevalence, transfusion requirements, and outcome. Crit Care Med. 2002;30(8):1765-71. pmid: 12163790

18. Thiery-Antier N, Binquet C, Vinault S, Meziani F, BoisrameHelms J, Quenot JP, et al. Is Thrombocytopenia an Early Prognostic Marker in Septic Shock? Crit Care Med. 2016;44(4):764-72. doi: 10.1097/CCM.0000000000001520 pmid: 26670473

19. Sezgi C, Taylan M, Kaya H, Selimoglu Sen H, Abakay O, Demir $\mathrm{M}$, et al. Alterations in platelet count and mean platelet volume as predictors of patient outcome in the respiratory intensive care unit. Clin Respir J. 2015;9(4):403-8. doi: 10.1111/crj.12151 pmid: 24725778

20. Caruso P, Ferreira AC, Laurienzo CE, Titton LN, Terabe DS, Carnieli DS, et al. Short- and long-term survival of patients with metastatic solid cancer admitted to the intensive care unit: prognostic factors. Eur J Cancer Care (Engl). 2010;19(2):2606. doi: 10.1111/j.1365-2354.2008.01031.x pmid: 19709168

21. Rice TW, Wheeler AP. Coagulopathy in critically ill patients: part 1: platelet disorders. Chest. 2009;136(6):1622-30. doi: 10.1378/chest.08-2534 pmid: 19995764

22. Greinacher A, Selleng K. Thrombocytopenia in the intensive care unit patient. Hematology Am Soc Hematol Educ Program. 2010;2010:135-43. doi: 10.1182/asheducation2010.1.135 pmid: 21239783

23. Marco-Schulke CM, Sanchez-Casado M, Hortiguela-Martin VA, Quintana-Diaz M, Rodriguez-Villar S, Perez-Pedrero MJ, et al. [Severe thrombocytopenia on admission to the intensive care unit in patients with multiple organ failure]. Med Intensiva. 2012;36(3):185-92. doi: 10.1016/j.medin.2011.09.011 pmid: 22296738

24. Neame PB, Kelton JG, Walker IR, Stewart IO, Nossel HL, Hirsh J. Thrombocytopenia in septicemia: the role of disseminated intravascular coagulation. Blood. 1980;56(1):88-92. pmid: 6446336

25. Prina E, Ferrer M, Ranzani OT, Polverino E, Cilloniz C, Moreno E, et al. Thrombocytosis is a marker of poor outcome in community-acquired pneumonia. Chest. 2013;143(3):76775. doi: $10.1378 /$ chest.12-1235 pmid: 23187959

26. Valente C, Soares M, Rocha E, Cardoso L, Maccariello E. The evaluation of sequential platelet counts has prognostic value for acute kidney injury patients requiring dialysis in the intensive care setting. Clinics (Sao Paulo). 2013;68(6):803-8. doi: 10.6061/clinics/2013(06)13 pmid: 23778497 